\title{
Research on Comprehensive Budget Management of Agricultural Enterprises in Heilongjiang under the Background of Cloud Accounting
}

\author{
Xiao Nanyun ${ }^{1, \mathrm{a}}, \mathrm{Xu}$ Yan $^{1, \mathrm{~b}}$ \\ ${ }^{1}$ Harbin Finance University, Department of Accounting, Harbin, Heilongjiang, China
}

\begin{abstract}
Heilongiiang, as an important commodity grain production base in the country, shoulders the important task of national food security. At the same time, Heilongjiang has strong supporting capacity in resources, industries, science and education, talents, infrastructure and so on. Therefore, it plays an important role in the overall development of the country. Accounting, as an important management means and information system, is affected by economic environment factors. Accounting should adapt to the new economic environment, and provide a boost to the economy. The budget is not only a tool to control expenditure, but also a method to increase the value of the enterprise by using the existing resources of the enterprise. In the 21st century, with the rapid development of computer and internet technology, cloud computing and big data have gradually become the mainstream technology. In the era of big data, it is imperative to carry out comprehensive budget management in the environment of cloud accounting.
\end{abstract}

\section{Introduction}

Cloud accounting is a kind of accounting information system based on cloud computing, which is composed of professional software and hardware. Cloud accounting has real-time, sharing advantages, can promote the rapid transfer of information in the group between departments, and strengthens communication between departments, thus improving work efficiency. Relying on the ability of collecting, storing, screening and analyzing huge amount of data, it provides accurate and reliable data information for the management of enterprises.

\section{The Application Foundation of comprehensive budget management under the cloud accounting of Agricultural Enterprise}

\subsection{Centralize the Establishment of Cloud Accounting Centers}

The foundation of building cloud accounting platform is to build cloud accounting center. According to the actual situation, agricultural enterprises set up cloud accounting center under the financial department of the group and accept the leadership of the head of the financial department. The establishment of cloud accounting center in the headquarters has a strong geographical advantage, the geographical location of subordinate units is relatively scattered, and they undertake more agricultural production tasks. The establishment of cloud accounting center can have better network infrastructure environment and talent advantages.

\subsection{Customized Software and Hardware}

Comprehensive budget management should be reset and divided into functions according to the requirements of cloud accounting, and it should be divided into budget decision-making organization, budget management organization and budget supervision organization. The budget decision-making body is composed of senior managers of the group, whose main responsibilities are to make decisions on the overall budget objectives, formulate the overall budget objectives in line with the strategy, establish the budget management committee, and approve the budget draft. The budget management organization is divided into the budget management department of the cloud accounting center and the budget management department at the grass-roots level. It is mainly responsible for the release of budget objectives, budget preparation, summary, implementation and adjustment [1]. The budget supervision organization is mainly composed of the budget management committee, the person in charge of the grass-roots financial department and the audit department, which supervises the budget implementation, strengthens the controllability of the budget and improves the budget preparation level.

\subsection{Introduce High-quality Comprehensive Talents}


The cloud accounting platform consists of budget management personnel and information technology maintenance personnel. The cloud accounting platform consists of budget management personnel and information technology maintenance personnel. The cloud accounting center sets up a budget department, and the budget management personnel are re divided to be responsible for the budget management at the grassroots level. The technical maintenance personnel shall be responsible for the daily maintenance of software and hardware to prevent the occurrence of system failure, resulting in data loss and other technical problems.

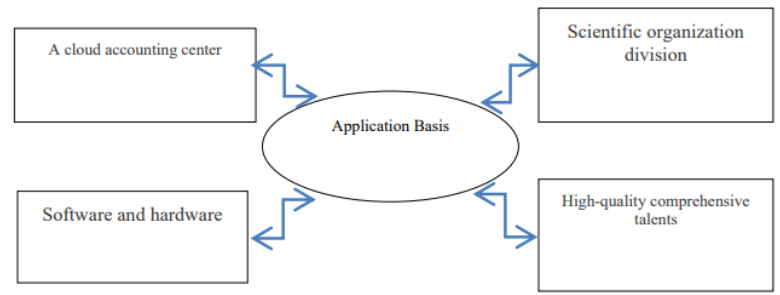

Fig1. Application basis of total budget management in agribusiness cloud accounting

\section{Construction of comprehensive budget management system of agricultural enterprises under cloud accounting}

The comprehensive budget management system of agricultural enterprises should reflect the characteristics of centralization, real-time and sharing, and need a lot of data collection, storage and analysis, while the big data and cloud accounting platform provide the necessary support for the construction and implementation of the comprehensive budget management system [2]. The architecture of cloud accounting can be generally divided into infrastructure layer, hardware virtualization layer, application layer, data layer and platform layer. Each layer is composed of corresponding services, namely, infrastructure services (IaaS), hardware services (HaaS), software services (SaaS), data services (DaaS) and desktop services (PaaS). Based on the strategic objectives, the comprehensive budget management workflow is divided into three parts: budget preparation, budget implementation and budget evaluation.

\subsection{Specific Description}

- The software as a service (SaaS) layer is used to standardize the business process (SOP) of budget management, including budget preparation, implementation and evaluation.

- The platform as a service (PaaS) layer is used to build the cloud storage service of budget management and the application service platform of budget management and business department integration.

- The data as a service (DaaS) layer is used to build and integrate the data resources of the group enterprise with the internal business information and external market environment information as the core.

- The hardware as a service (HaaS) layer is used to build the server cluster of data mining and strategic analysis model.

- Using the(IaaS)layer to form the effective distributed processing and elastic computing capability, finally forming the overall budget management framework model of group enterprises based on cloud accounting in the era of big data, forming a unified comprehensive budget management system.

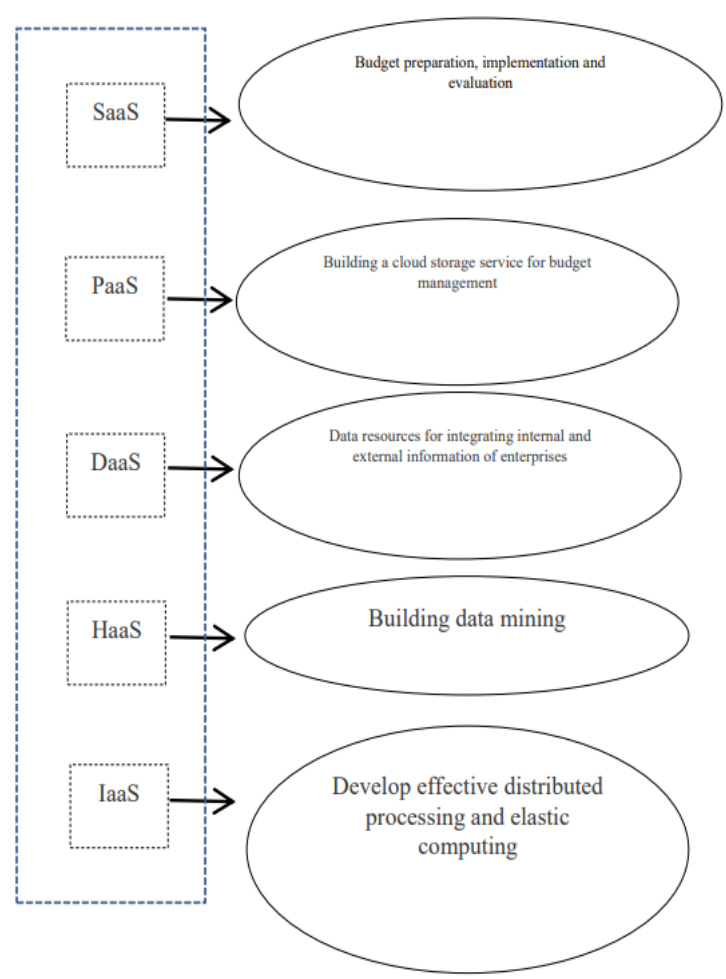

Fig2. Construction of comprehensive budget management system of agricultural enterprises under cloud accounting

\subsection{Assumption of Comprehensive Budget Management Mode under Cloud Accounting}

- Budget preparation based on cloud accounting. The comprehensive budget management under cloud accounting needs to strengthen the data analysis of the market environment according to the enterprise strategic objectives, and then formulate the budget preparation objectives scientifically combined with the current development status of the enterprise. Each budget organization will make scientific adjustment according to the needs of different departments, and the budget preparation method and budget table will be redefined, which is specifically reflected in the budget scheme, budget items and cross check relationship, etc., so as to eliminate the miscellaneous links, and realize the organic up-down organic circulation process with the help of cloud accounting platform [3]. Enterprise comprehensive budget management is a complex 
procedure, which is determined by the diversification of enterprises. Enterprises not only have many modules, but also involve a myriad of businesses. Under the cloud accounting environment, budgeting has the advantage of flexibility, and can provide personalized customization according to needs, so as to effectively realize the dynamic budgeting.

- Budget execution based on cloud accounting. Under the cloud accounting environment, the standardization of budget approval is realized, so as to strengthen the risk management and control, and decompose the risk to people, so as to improve the efficiency of budget approval. At the same time, the illegal examination and approval will be reduced to the minimum degree, such as approval beyond authority, repetitive approval, etc., so that the approval is more and more transparent and efficient. Under the influence of budget control, the ability of comprehensive budget analysis and control in cloud accounting environment will be improved, and the whole process budget control will be formed, including before, during and after the event. With the advantages of cloud accounting, the data information will be centralized to the cloud data center for effective data analysis, so as to give early warning to the abnormal budget and make dynamic adjustment to ensure the realization of budget objectives.

- Budget evaluation based on cloud accounting. The most significant advantage of budget evaluation based on cloud accounting is the combination of budget and enterprise business, which realizes a comprehensive management and control system, including strategic control, budget control and performance, so as to play the guiding role of budget evaluation and stimulate the enthusiasm of different budget entities. The budget evaluation based on cloud accounting needs to establish a corresponding evaluation system, update the data in time, and realizes the real-time data transmission. The evaluation system based on cloud accounting will effectively integrate the data information of enterprise employees and improve the objectivity of evaluation.

\section{Suggestions on improving the overall budget management level of agricultural enterprises based on cloud accounting}

\subsection{Improve theLevel of Budgeting.}

The comprehensive budget management based on cloud accounting can effectively avoid the problems of information isolation and single budget mode. In the cloud accounting platform, multidimensional data is integrated in the platform, breaking through time and space, internal and external. The information required by the budget is screened and analyzed in the data processing center of the platform to provide personalized budget scheme [4].
Combined with the sharing advantages of cloud accounting platform, it can promote the communication and contact between organizations and strengthen the overall strategic awareness. Cloud accounting service has the characteristics of customization on demand. Agricultural enterprises can make budget according to their own situation and realize the personalization of budget preparation. By strictly controlling the authority of employees, the budget departments can effectively participate in the budget, and avoid the adverse impact on the efficiency of budget preparation due to excessive centralization of management. According to the different business and functions of each department, different budgeting methods can also be adopted in the group. Meanwhile, cloud accounting can be used to obtain the internal and external dynamic information of the enterprise in real time, so as to adjust and improve the budget preparation in time. The budget preparation has truly realized the cycle mode of top-down, bottom-up and top-down combination, shortened the budget preparation cycle, promoted the development of budget preparation at a higher level, and made the budget more reasonable and objective.

\subsection{Strengthen the Monitoring of Budget Implementation.}

The comprehensive budget management system based on cloud accounting platform can effectively reduce the time of examination and approval. The budget decision-making organization and budget management committee can audit the budget draft anytime and anywhere in the system, and the approval process of budget scheme on the cloud accounting platform can be more transparent. After the budget is approved, the budget management committee will upload the budget to the cloud platform, and each budget entity can obtain the budget data in real time and execute the budget. The budget implementation process needs to be effectively controlled. Budget control is the key link to ensure the effect of budget implementation [5]. Cloud accounting platform can realize the control and supervision of the whole operation of the enterprise. The strict authority mechanism is used to ensure the effectiveness of the control. Users who exceed the budget or do not have permission are limited to enter operations. If repeated operations occur, the system will issue an early warning in time. Only the personnel with higher authority can operate and enter normally after approval. This way of budget authority management can better find out the problems that are inconsistent with the budget in the actual business, and timely feedback, so as to prevent deviation from the budget target.

\subsection{Improve the Budget Evaluation Mechanism.}

Comprehensive budget management increases the link of budget assessment and evaluation. From the perspective of the whole production and operation cycle, efficient budget evaluation can provide guidance for the preparation of comprehensive budget in the future, reflect the rationality of budget preparation, test whether the 
budget target is achieved, and through appropriate rewards and punishments, it can stimulate the enthusiasm of employees and cultivate enterprise cohesion. Comprehensive budget management takes the budget as the standard to evaluate the performance of employees, which can give full play to the initiative of each budget unit, so as to achieve the budget objectives. In order to make the budget evaluation more reasonable and humanized, the real-time data of cloud accounting platform is used to realize the assessment and evaluation of the budget implementation process, not just to evaluate the results of budget implementation, so as to improve the comprehensiveness and objectivity of budget evaluation.

\subsection{Establish Feedforward Control Mechanism to Realize Budget Control Effectively.}

In order to make the comprehensive budget management can effectively play its management and control functions, we should make full use of the massive data provided by the cloud accounting platform to repeatedly forecast, control the possible situation in advance, compare the budget target to be achieved by the plan with the forecast data, and set a critical point of problems, which can be accurate before the critical point is reached If the problem is found, the modification measures can be formulated before the problem occurs, so as to solve the problem in the bud. Cloud accounting platform provides managers with real-time business information and feedback information, which is used to control and analyze the budget implementation, and track it in real time. It can timely find problems in the implementation process, thus avoiding some controllable risks.

\section{Conclusion}

The development of cloud accounting in the era of big data brings new ideas for enterprises to promote the informatization of comprehensive budget management. Combined with the characteristics of cloud accounting technology, this paper establishes a comprehensive budget management framework model of agricultural enterprises, analyzes the functional application of the three core modules of budget preparation, budget implementation and budget evaluation, hoping to provide certain theoretical guidance and application reference for the related fields of subsequent budget management informatization research.

\section{Acknowledgment}

Project source: 2018 Heilongjiang Provincial Universities Basic Scientific Research Business Expenses Scientific Research Project, No.2018-KYYWF-014

\section{References}

1. Tan Jie, Cloud accounting characteristics analysis and practical application research based on big data background $[\mathrm{J}]$. Modern economic information. 2015(01).

2. Cheng Wendong, Construction of enterprise comprehensive budget management system based on EVA[J]. Accounting correspondence, 2018(32).

3. Zhang Jian, Comprehensive budget management based on cloud computing environment. [J]. Accounting correspondence, 2016(04).

4. Zhu Xiumei, Research on enterprise comprehensive budget management under big data and cloud accounting[J]. Friends of accounting. 2018(08)

5. Alfred Tat-Kei Ho. From Performance Budgeting to Performance Budget Management: Theory and Practice[J]. Public Administration Review . 2018 (5) 